\title{
Medical evaluation and management of male and female voiding dysfunction: a review
}

\author{
ALANA MURPHY, SETH TEPLITSKY, AKHIL K. DAS, JOON YAU LEONG, ANDREW MARGULES, COSTAS D. LALLAS
}

Department of Urology, Sidney Kimmel Medical College at Thomas Jefferson University, Philadelphia, PA

\begin{abstract}
A significant workforce shortage of urologists available to serve the US population has been projected to occur over the next decade. Accordingly, much of the management of urologic patients will need to be assumed by other specialties and practitioners. Since primary care physicians are often first evaluate common urologic complaints, it makes sense that these physicians are in an excellent position to intervene in the management of these patients when appropriate. One of the most common complaints in urology is voiding dysfunction. The incidence of voiding dysfunction increases with age, with conservative estimates showing that over $50 \%$ of elderly patients suffer. Despite this high prevalence and its negative impact on quality of life, however, few seek or receive treatment, as many do not readily disclose these impactful yet personal symptoms. We sought to summarize the typical presentation, evaluation, assessment and therapeutic options for both male and female patients presenting with voiding dysfunction.
\end{abstract}

Key words: urology, urinary incontinence, referral and consultation, urination disorders, disease management.

\section{INTRODUCTION}

Voiding dysfunction is a term used to describe the many conditions resulting from impairment within the lower urinary tract, including the bladder, prostate (in men), and urethra. This is a widespread problem that is estimated to affect over half of the elderly population in this country [1]. It is estimated that $5 \%$ of men between the age of $20-44$ and $17 \%$ of women over the age of 20 suffer from voiding dysfunction such as incontinence, which makes up a large percentage of this dysfunction [2, $3]$. However, due to the fear of disclosing these embarrassing symptoms, this value is often underestimated. Furthermore, voiding dysfunction is costly, with incontinence alone estimated to cost $\$ 19.5$ billion in 2000 [4]. Since that time, the prevalence of voiding dysfunction has continued to increase. In addition to this widespread problem, the physicians who historically have managed these patients, namely urologists, are suffering from an impending workforce shortage. There has been a decreasing supply of urologists relative to population growth over the last ten years which will only continue to widen in the future [5]. Given that the average patient age managed by urologists is one of the highest among specialties, it is essential that other clinicians carry a primary role in the treatment of voiding dysfunction as well. Hence, familiarity with the signs and symptoms, evaluation and treatment options, as well as recognition of when a urology referral is necessary, are critical so that patients may receive timely and effective treatment.

\section{MALE VOIDING DYSFUNCTION}

\section{MALE STRESS URINARY INCONTINENCE (SUI)}

Stress urinary incontinence (SUI) is an involuntary loss of urine during physical exertion or physical activity [6]. Men who have undergone surgical treatment or radiation therapy for prostatic conditions, such as an enlarged prostate or cancer, have an increased risk of developing SUI [7]. Men who undergo multiple prostatic treatments have a substantially higher risk of developing SUI when compared to those who have only undergone a single treatment modality.

\section{Pathophysiology}

SUI occurs when the urethral resistance cannot overcome the increased intravesical pressure, which primarily comes from the abdomen. In the male patient, significant risk factors for SUI include increasing age and prior prostate procedures [8]. SUI is usually the result of post-surgical or postradiation changes in the lower urinary tract. The internal sphincter is located at the juncture of the bladder neck and prostate, and is therefore 
susceptible to damage during endoscopic procedures, while the external sphincter is made up of the musculature of the pelvic floor. This disease process is thought to be due to injury to the internal urinary sphincter and a lack of mobility of the external sphincter [9].

\section{Table 1}

This table provides a brief summary of voiding dysfunctions diagnoses, how to identify via history taking, and when urologic referral is indicated

\begin{tabular}{|c|c|c|}
\hline Condition & Clinical History & Indication for Urologic Referral \\
\hline Stress Urinary Incontinence (SUI) & $\begin{array}{l}\text { Urinary incontinence with Valsalva } \\
\text { maneuvers (e.g. coughing, laughing, } \\
\text { sneezing, running) }\end{array}$ & $\begin{array}{l}\text { 1. Inadequate clinical improvement following pelvic floor } \\
\text { muscle therapy } \\
\text { 2. Patient preference for surgical intervention }\end{array}$ \\
\hline Over Active Bladder (OAB) & $\begin{array}{l}\text { Sudden compelling desire to void } \pm \\
\text { urinary frequency }\end{array}$ & $\begin{array}{l}\text { 1. Inadequate clinical improvement follow behavioral } \\
\text { modifications (fluid management and minimization of } \\
\text { bladder irritants) + failure to respond to } 1 \text { or } 2 \text { OAB } \\
\text { medications } \\
\text { 2. Concern for incomplete bladder emptying } \\
\text { 3. Patients with neurogenic bladder (e.g. multiple } \\
\text { sclerosis, Parkinson's disease, spinal cord injury) } \\
\text { 4. Patients with gross or microhematuria }\end{array}$ \\
\hline \begin{tabular}{|l|} 
Urge Urinary Incontinence (UUI) \\
\end{tabular} & $\begin{array}{l}\text { Urinary incontinence associated with } \\
\text { urgency (not able to make it to the } \\
\text { bathroom in time) }\end{array}$ & $\begin{array}{l}\text { 1. Inadequate clinical improvement following behavioral } \\
\text { modifications (fluid management and minimization of } \\
\text { bladder irritants) }+ \text { failure to respond to } 1 \text { or } 2 \text { OAB } \\
\text { medications } \\
\text { 2. Concern for incomplete bladder emptying } \\
\text { 3. Patients with neurogenic bladder (e.g. multiple sclerosis, } \\
\text { Parkinson's disease, spinal cord injury) } \\
\text { 4. Patients with gross or microhematuria }\end{array}$ \\
\hline $\begin{array}{l}\text { Lower Urinary Tract Symptoms } \\
\text { (LUTS) from Benign Prostatic } \\
\text { Hyperplasia (BPH) }\end{array}$ & $\begin{array}{l}\text { Irritative voiding symptoms (urinary } \\
\text { frequency, urgency, urge incontinence } \\
\text { and nocturia) and obstructive voiding } \\
\text { symptoms (weak urinary flow rate, } \\
\text { straining, urinary retention, overflow } \\
\text { incontinence) }\end{array}$ & $\begin{array}{l}\text { 1. Failure to respond to } 1 \text { or } 2 \mathrm{BPH} \text { medications } \\
\text { 2. Patient preference for surgical intervention } \\
\text { 3. Concern for incomplete bladder emptying or retention } \\
\text { 4. Renal impairment } \\
\text { 5. Patients with gross or microhematuria } \\
\text { 6. Abnormal digital rectal exam or elevated prostate specific } \\
\text { antigen }\end{array}$ \\
\hline $\begin{array}{l}\text { Overflow Urinary Incontinence and } \\
\text { Detrusor Underactivity }\end{array}$ & $\begin{array}{l}\text { Symptoms of storage, such as nocturia, } \\
\text { urgency, and frequency, or a lack of } \\
\text { any urge to void at all which may } \\
\text { cause overflow incontinence }\end{array}$ & 1. Upon diagnosis for proper testing and management \\
\hline $\begin{array}{l}\text { Interstitial Cystitis (IC)/Bladder } \\
\text { Hypersensitivity }\end{array}$ & $\begin{array}{l}\text { Increased discomfort (sensations of } \\
\text { pressure, pain, or spasms of the supra- } \\
\text { pubic or urethral regions) with bladder } \\
\text { filling and immediate relief with } \\
\text { voiding }[47,48]\end{array}$ & $\begin{array}{l}\text { 1. Inadequate clinical improvement following behavioral } \\
\text { modifications (heat and cold to area of discomfort, } \\
\text { minimization of causative agents) } \\
\text { 2. Inadequate clinical improvement following first line } \\
\text { medications } \\
\text { 3. Patient preference for surgical intervention }\end{array}$ \\
\hline Dysfunctional Voiding (DV) & $\begin{array}{l}\text { Urinary storage symptoms (nocturia, } \\
\text { urgency, fruqency) along with in- } \\
\text { continence throughout the day }\end{array}$ & $\begin{array}{l}\text { 1. Inadequate clinical improvement following lifestyle } \\
\text { modifications } \\
\text { 2. Patient preference for surgical intervention }\end{array}$ \\
\hline Bladder Neck Dysfunction (BND) & $\begin{array}{l}\text { Hesitancy, pelvic discomfort, fre- } \\
\text { quency, urgency, hesitancy and sense } \\
\text { of incomplete emptying or impaired } \\
\text { stream }\end{array}$ & $\begin{array}{l}\text { 1. Inadequate clinical improvement following first line } \\
\text { medication (alpha-adrenergic antagonists) }\end{array}$ \\
\hline
\end{tabular}

\section{Clinical presentation}

Men with SUI usually describes leakage of urine with physical activity or Valsalva maneuvers such as coughing, laughing or lifting anything heavy. Often, they wear pads or diapers to conceal the leakage. SUI generally does not pose a significant medical issue but has a negative impact on quality of life and independence, and poses a financial burden due to the cost of daily pads or diapers [9].

\section{Assessment and diagnosis}

Obtaining a detailed voiding and leakage history from the patient is the first step in identifying SUI in men. Differentiating SUI from urge urinary incontinence (UUI), overflow urinary incontinence, or mixed urinary incontinence may be difficult, but remains critical since treatments differ. These are usually distinguished by careful history taking. Occasionally, urodynamic study and/or cystoscopy from an urologist are necessary 
to confirm the diagnosis. It is critical to uncover the duration of symptoms and severity, as well as to assess whether the patient is distressed. Those who are not troubled by their leakage rarely require treatment. Severity can be evaluated by the number of pads or diapers used per day if the patient is using such, with pad weight further helping quantify the degree of leakage, as some patients are more fastidious about changing. When performing an exam of the abdomen and external genitalia, the patient's bladder should be full. Urinary leakage demonstrated when the patient bears down (Valsalva maneuver) is pathognomonic for SUI. However, demonstration of SUI in the office, although helpful, is not required for nonsurgical or surgical intervention.

\section{Nonsurgical treatment}

Once reversible causes are excluded, nonsurgical options are the first line of therapy for the management of SUI before surgical intervention. Lifestyle interventions are the first step, with recommendations for decreasing caffeine intake, promotion of weight loss, and encouragement for smoking cessation [9]. If lifestyle modifications do not succeed, further treatments include daily pelvic floor muscle therapy regimens such as Kegel exercises. As many patients are not able to correctly perform Kegel exercises, a pelvic floor physical therapist may be helpful for those patients, aiding them in identifying the precise muscles required for training [10]. Overall, Kegel exercises have been shown to decrease the severity of leakage and improve quality of life scores for those patients suffering from SUI [11]. Medical therapies, such as with antimuscarinic medications, have shown limited success in treating SUI [12] and are most effective in patients with mixed incontinence. If a patient has tried these therapies for at least a year without improvement, surgical management for SUI can be considered.

\section{Surgical treatment}

Men with SUI impacting their quality of life can opt for surgical treatment after failing nonsurgical treatment. There are three surgical options for the management of SUI in men. The least invasive is a bulking agent injected near the bladder neck, meant to improve urethral coaptation. Short term success rates are poor at $43 \%$ [13]. The success of this procedure is dependent on urethral pliability to accommodate the bulking agent. Another option is to increase the urethral resistance via a male sling. The short-term results have been variable, at $42.9-79 \%$ continence depending on the sling type, with the long-term durability undetermined [14]. Lastly, the artificial urinary sphincter is currently the gold standard for the treatment of male SUI. Although the short-term success rates are excellent with the artificial urinary sphincter at $82 \%$, this implantable device has a higher risk of reoperation rate within 8 years [15]. Critically, the patient has to be willing and able to work the device on his own.

\section{LOWER URINARY TRACT SYMPTOMS (LUTS) AND BENIGN PROSTATIC HYPERPLASIA (BPH)}

Lower Urinary Tract Symptoms (LUTS) describe symptoms related to the lower urinary tract, including the bladder, prostate, and urethra. These symptoms are classified into obstructive and irritative to help identify the cause. Irritative symptoms include urinary frequency, urgency, urge incontinence and nocturia. Obstructive symptoms often include weak urinary flow rate, straining to urinate, urinary retention, and overflow urinary incontinence. In men the most common cause of LUTS is Benign Prostatic Hyperplasia (BPH), which can have either irritative or obstructive voiding symptoms.

\section{Pathophysiology}

There are many theories to the cause of LUTS from BPH, but most agree that the hyperplasia of the prostatic cells within the prostatic urethra is responsible for some of the urinary symptoms [16]. In particular, obstructive symptoms are thought to be due to compression of the urethra caused by hypertrophy of the prostate. As for the irritative symptoms, it is believed to be due to the prostate obstructing the bladder outlet with resultant hypertrophy of the bladder wall muscle.

\section{Clinical presentation}

The clinical presentation of BPH is variable, but most men present with complaints of LUTS. These men are usually over 50, with concerns including both obstructive and irritative symptoms of varying severities. The risk of developing BPH increases with age and can be high as $70 \%$ in men over the age of 75 [17]. The most commonly reported symptoms include nocturia, daytime frequency, and a feeling of incomplete voiding. The development of symptoms is gradual, over several years, which may make these symptoms challenging to notice. 


\section{Assessment and diagnosis}

The first step in evaluation is a detailed history querying the duration and progression of the patient's urinary symptoms. Physicians should also assess the impact of LUTS on the patient's quality of life. Both goals can be accomplished using International Prostate Symptoms Score (IPSS) questionnaire. Next, a urinalysis is needed to rule out infection and hematuria. A physical exam should include a digital rectal exam (DRE) to check the prostate enlargement, as well as a discussion regarding prostate cancer screening including blood PSA testing. Elevated PSA results should prompt a urology consult. Non-invasive testing including urinary flow rate and a post-void residual (PVR) ultrasound scan can be helpful in assessing the severity. Low flow rates and high PVR values both increase the suspicion for BPH. In complicated clinical scenarios where neurogenic bladder dysfunction or overactive bladder may be occurring concurrently with $\mathrm{BPH}$, a urodynamic evaluation is helpful. In these cases, seeking a urological consultation is immensely beneficial for patient management. $\mathrm{BPH}$ is a clinical diagnosis, and the decision to treat is based on the severity of symptoms, evidenced by a high PVR volume, UTI, and extent of negative impact on QOL experienced by the patient. Accordingly, BPH is mostly a disease affecting QOL, but it can lead to more serious medical complications such as urosepsis, bladder stones, and renal insufficiency due to chronic outlet obstruction.

\section{Non-surgical treatment}

The first line of treatment for LUTS from $\mathrm{BPH}$ is non-surgical therapy. Depending on the most prominent symptoms, patients may also be advised to undergo behavioral modifications. For example, patients with prominent nocturia may be counseled to limit their fluid intake after dinner to decrease symptom severity. For medications, alphablockers are the first line therapy and the most common treatment modality for the management of $\mathrm{BPH}$ [18]. A significant side effect is hypotension, which can limit its use. Patients unable to take alpha-blockers or who fail treatment can be started on 5-alpha reductase inhibitors. Patients on both these medications for their treatment of BPH are considered to be on maximal medical therapy. Newer studies have suggested that Tadalafil may be helpful in patients with LUTS, with a mechanism similar to that of alpha-blockers [19]. Patients considering further intervention will need to be referred to an urologist.

\section{Minimally invasive therapy (MIT)}

MITs have become very popular in the treatment of BPH because they are outpatient procedures. MIT is reserved for patients that are failing medical therapy or considering coming off medical therapy. These therapies aim to decrease the amount of prostatic obstruction to the urethra. Some of the common minimally invasive therapies include a urethral lift procedure (UroLift) and steam therapy (Rezum). These are newer technologies with limited long term data, compared to older MIT such as transurethral needle ablation (TUNA), which is no longer recommended and transurethral microwave therapy (TUMT), which has been shown to have higher reoperations rates than other options. MITs are outpatient procedures, requiring no general anesthesia and are associated with less sexual side effects, such as retrograde ejaculation, which can be prominent in the surgical therapies [20]. These advantages make MIT a very desirable option for a patient suffering from BPH.

\section{Surgical therapy}

Surgical therapy is reserved for those who have failed medical therapy, or who are unwilling to continue medications or use other therapies. There are several surgical therapies available for $\mathrm{BPH}$, with the gold standard being TURP. TURP is now considered size independent, though larger prostates above 80-100 grams, are often considered for other procedures. Alternatively, Holmium laser enucleation of the prostate (HoLEP) is a promising procedure that can treat any size prostate endoscopically. Other techniques include ablative procedures, such as the Green Light, Diode laser ablation of the prostate, and Aquablation which uses high velocity water jets to ablate prostatic tissue. Another option is the transurethral incision of the prostate (TUIP), which is recommended for prostates below 30 grams. The decision for which type of surgery is discussed between the urologist and the patient based on patient characteristics and preference.

\section{OVERACTIVE BLADDER (OAB), URINARY URGE INCONTINENCE (UUI)}

Overactive active bladder (OAB) syndrome represents an array of symptoms including urinary urgency, frequency, and urge incontinence (UUI). UUI is defined as the sudden, involuntary loss of urine associated with feelings of urgency to void. The hallmark OAB syndrome is urinary urgency and may be accompanied by UUI [21]. Men with 
these symptoms should also be evaluated for BPH since LUTS and OAB often overlap. Urinary tract infections, prostatitis, and cystitis should be ruled out with urine cultures before starting treatment for OAB.

\section{Pathophysiology}

The pathophysiology of idiopathic OAB syndrome is poorly understood and currently thought to be multifactorial [22]. Some neurologic conditions, such as multiple sclerosis and Parkinson's disease, can cause bladder overactivity and be mistaken for idiopathic $\mathrm{OAB}$ syndrome. It is important to rule out these conditions before initiating treatment for OAB. Additionally, patients with bladder outlet obstruction from BPH can also have symptoms that can be mistaken for $\mathrm{OAB}$ and must be ruled out. Other causes of urinary symptoms that mimic $\mathrm{OAB}$ include bladder cancer, non-infectious cystitis, and prostatitis. All should be ruled out before beginning treatment of $\mathrm{OAB}$.

\section{Clinical manifestation}

Men with OAB will often describe episodes of a sudden need to void without much warning, often struggling to make it to the bathroom before the initiation of voiding. OAB can be divided into two separate subtypes - dry and wet. Patients with dry $\mathrm{OAB}$ have severe urgency but denie episodes of urinary incontinence. Conversely, wet $\mathrm{OAB}$ is urinary urgency commonly associated with incontinence. Wet $\mathrm{OAB}$ comprises $33 \%$ of $\mathrm{OAB}$ cases [23].

\section{Assessment and diagnosis}

Men with $\mathrm{OAB}$ will report some degree of urinary urgency that is affecting their daily life. It is important first to confirm that the patient is experiencing UUI, rather than SUI or mixed incontinence. A detailed history, including duration and severity of symptoms, is important. Severity can be assessed by the number of pads used per day if the patient is using pads. A bladder diary documenting fluid intake, urine output, and voiding episodes can be given to the patient to complete before future office visits and can be helpful for decision making. OAB symptoms in men over 50 present a challenging situation for the clinician due to the increased risk of concomitant $\mathrm{BPH}$, and the large amount of overlapping symptoms between the two conditions. Patients that have bladder outlet obstruction from $\mathrm{BPH}$ and $\mathrm{OAB}$ syndrome should be evaluated by an urologist.

\section{Nonsurgical treatment}

Management of $\mathrm{OAB}$ syndrome begins with non-surgical intervention. Behavioral modification is the first step. Patients should be adequately counseled on avoiding bladder irritants such as caffeine, alcohol, artificial sweeteners, as well as preventing dehydration or overhydration. Modifications in behavior are often effective in reducing the symptoms of OAB and UUI [24]. The role of a pelvic floor physical therapist in this clinical situation may be helpful, but it is not as well established for men as it is in women.

Most experts agree that BPH should be treated before the initiation of medical therapy for $\mathrm{OAB}$ [25]. Treating BPH first is done to avoid the risk of causing urinary retention, a side effect of many OAB treatments. Occasionally, pharmacotherapy for BPH can also lead to symptomatic relief of OAB. These clinical situations can be difficult, and a referral to a specialist is warranted.

Men who continue to have isolated $\mathrm{OAB}$ syndrome after behavioral modification, in the absence of BPH or neurologic bladder dysfunction, are candidates for pharmacologic therapy. Two main classes of OAB medications exist - antimuscarinics and beta-3 agonists. No conclusive evidence supports the use of one $\mathrm{OAB}$ medication over the other, although each has a different side effect profile which should be considered when deciding. Bladder diaries should be obtained before and after the initiation of medical therapy to judge the effectiveness of the medication. The efficacy of the drug requires a minimum of 4-6 weeks before alternative therapies are considered.

\section{Surgical treatment}

Men with isolated $\mathrm{OAB}$ that have failed nonsurgical treatment should be referred to an urologist. Posterior tibial nerve stimulation (PTNS), an outpatient procedure performed by an urologist, is offered on a weekly basis for 6 weeks. This is a minimally invasive form of neuromodulation that has been proven effective in the treatment of $\mathrm{OAB}$, working as well as medications but with less side effects [26].

Other surgical treatments available include intradetrusor Botox ${ }^{\circledR}$ injections and sacral neuromodulation therapy (Interstim $\AA$ ). Intradetrusor Botox injections can be performed in the office without anesthesia while implantation of the Interstim devices requires a procedure with sedation or general anesthesia in the operating room setting. 


\section{OVERFLOW URINARY INCONTINENCE AND DETRUSOR UNDERACTIVITY (DUA)}

Detrusor underactivity (DUA) is a cause of urinary incontinence due to overflow. DUA occurs due to incomplete emptying of the bladder due to decreased contractile strength. This can have significant impacts on quality of life, with both voiding and storage symptoms present. DUA and overflow incontinence condition is seen more prevalently in the elderly population, with some studies showing that $48 \%$ of men over the age of 70 are affected by this condition [27]. The presence of bladder outlet obstructions can further complicate this condition.

\section{Pathophysiology}

The pathophysiology of detrusor underactivity is poorly understood, in part due to the many possible causes of this condition, such as myogenic, neurogenic, or idiopathic. Underactivity may be the result of poor detrusor muscle function or poor neurological control with problems possible at any point in the neurological pathway [28]. It is currently thought that age, diabetes, and other neurological risk factors such as stroke or neurodegenerative disease all confer a high risk for DUA. Current research is assessing the possibility of urothelial dysfunctions role in the DUA process [29]. This work suggests that impaired signaling and sensory transduction from the urothelium itself may play a role in DUA.

\section{Clinical manifestation}

There are no specific symptoms associated with this disorder. The symptoms seen with DUA mimic those of bladder outlet obstruction and overactive bladder [30]. Patients may present with symptoms of storage, such as nocturia, urgency, and frequency. It is also possible patients may lack any urge to void at all, and may present with DUA and overflow incontinence in this manner as well. Generally speaking, these patients have a weak stream with incomplete emptying if they can void. A further complication is added in patients with a neurological disease which alters sensation.

\section{Assessment and diagnosis}

Diagnosis of this condition can be difficult, as test results often have very similar findings in detrusor underactivity and bladder outlet obstruction. Utilizing flow rate and PVR testing is inadequate for this reason. Urodynamics is the only accepted method to diagnose detrusor underactivity, with results showing low pressure and low flow indicative of underactivity [28, 30, 31].

\section{Treatment}

Overall this is a significantly under-researched condition. These patients should be referred to an urologist both for testing to confirm the diagnosis, as well as management. Treatment options attempt to prevent complications and improve contractile strength. Currently, there is a lack of any data showing medications as beneficial. As many of these patients have concurrent bladder outlet obstruction, there have been attempts to relieve this obstruction in hopes of improving DUA symptoms. This approach has shown poor results, with many patients having unsatisfactory outcomes after prostate reducing procedures [32]. Electrical stimulation of the bladder via an implantable device has also been a topic of interest for these patients. In the very limited patients who have undergone this procedure, there have been significant increases in voided volume and a reduction in PVR volume [33], though this may not work well in all patients [34]. Other approaches to treatment include placement of a suprapubic catheter to drain the bladder, or urinary diversion to avoid complications.

\section{FEMALE VOIDING DYSFUNCTION}

\section{FEMALE STRESS URINARY INCONTINENCE (SUI)}

\section{Pathophysiology}

SUI occurs when urethral resistance is overcome by increased intra-abdominal pressure, and should be thought of as "activity related incontinence". In female patients, SUI is the result of poor mucosal coaptation (intrinsic sphincter deficiency), lack of peri-urethral support structures (Hammock hypothesis), or a combination of factors [35]. Risk factors for developing SUI include pregnancy and childbirth, increasing age, obesity, previous pelvic surgery, and chronic cough.

\section{Clinical presentation}

Women with SUI will complain of urinary incontinence while coughing, laughing, or sneezing. Women may also complain of incontinence during a spectrum of physical activities (e.g., brisk walking to high impact jumping). Although it does not pose a medical threat to most patients, SUI can have a negative impact on a woman's quality of life [36]. 


\section{Assessment and diagnosis}

While obtaining a clinical history, some women may offer a clear history of SUI and others may need help determining if they experience SUI, urgency urinary incontinence, or mixed urinary incontinence (both stress and urgency incontinence). "What are you doing when you leak?" is an effective way to start the conversation. History should include duration of incontinence, severity (number of pads per day), and degree of bother. SUI that is not bothersome often does not require clinical intervention. A limited pelvic exam to demonstrate leakage while a patient coughs or bears down can help solidify the diagnosis, but it is not required for non-surgical treatments.

\section{Non-surgical treatment}

SUI can be managed with non-surgical interventions. Women who perform daily pelvic floor muscle therapy (PFMT) regimens (e.g. Kegel exercises) report significant improvement in validated SUI bother scores and quality of life metrics [37]. If woman interested in following a PFMT regimen at home, proper Kegel technique should be reviewed in the office or patients should be referred to a pelvic floor physical therapist for proper instruction. While many women may recognize the term "Kegel exercise," nearly half of women do not perform Kegel exercises correctly [38]. In addition to PFMT, vaginal inserts provide mechanical support at the level of the urethra and subsequently reduce the severity of SUI. Although continence pessaries are to be managed by a specialist, women can be instructed to use an over the counter product that is inserted like a tampon (Poise $\AA$ Impressa $\AA$ ). These easily accessible products are best for use during situations when women increase their physical activity level (e.g. trip to the gym). Non-surgical management options for SUI are associated with minimal risk and should be offered to all patients with bothersome SUI before pursing specialty referral.

\section{Surgical treatment}

Women with SUI who have failed nonsurgical treatment or who do not wish to pursue non-surgical treatments should be referred to a specialist. Surgical treatments available include peri-urethral bulking agents and various types of urethral slings. Injection of peri-urethral bulking agents is meant to improve urethral coaptation. Documented efficacy rates for peri-urethral bulking agents vary from $22-66 \%$, with only short term improvement in SUI [39]. Urethral slings offer superior success rates with short term success ranging from 62 to $97 \%$ [40]. Urethral slings can be made of polypropylene mesh, a biologic graft, or autologous fascia. Urethral slings remain the gold standard for the surgical management of SUI.

\section{OVERACTIVE BLADDER (OAB)/URGENCY URINARY INCONTINENCE (UUI)}

The hallmark of OAB syndrome is urinary urgency. OAB is usually accompanied by frequent urination with or without UUI. Women with OAB should not have a urinary tract infection or other obvious lower urinary tract pathology to explain their urinary urgency.

\section{Pathophysiology}

The pathophysiology of idiopathic $\mathrm{OAB}$ is not well understood and the etiology of OAB symptoms in most women is likely multifactorial. A number of neurologic conditions can promote bladder spasms (overactive detrusor muscle), including multiple sclerosis, Parkinson's disease, suprasacral spinal cord injuries, and previous cerebrovascular accidents. OAB symptoms can also manifest in patients with mechanical bladder outlet obstruction (e.g. pelvic organ prolapse), bladder cancer or noninfectious cystitis (e.g. radiation cystitis, painful bladder syndrome/interstitial cystitis).

\section{Clinical presentation}

Women with OAB suffer from a sudden need to void and "not enough warning time" to get to the bathroom. They often report frequent urination during the daytime and nocturia. Approximately one third of women with OAB syndrome will also complain of UUI episodes when they cannot get to the bathroom in time [41]. The prevalence of UUI is approximately $50 \%$ in OAB patients with diabetes [42].

\section{Assessment and diagnosis}

Women with OAB must report some degree of urinary urgency that is bothersome to them. Some women may also offer a clear history of UUI and other women may need help determining if they experience UUI, SUI, or mixed urinary incontinence. "What are you doing when you leak?" is a good way to start the conversation. The history should include duration of symptoms, the severity of their incontinence (number of pads per day) if they complain of UUI, and degree of bother. 


\section{Non-surgical treatment}

Treatment of women with bothersome OAB and UUI should start with non-surgical interventions. The treatment algorithm should always include behavioral modifications, which may dramatically improve OAB symptoms and UUI. These women should be counseled to minimize their intake of bladder irritants and to avoid dehydration or overhydration. If a patient cannot provide a reliable fluid intake history, then a 3 day bladder diary is helpful to identify bladder irritants, capture instances of fluid mismanagement, and document just how frequently these women are voiding and having episodes of UUI [43]. Beyond behavioral modifications, women can participate in PFMT regimens with or without the guidance of a pelvic floor physical therapist.

Those who continue to have bothersome symptoms following behavioral modification are candidates for pharmacologic therapy. There are two classes of OAB medications, anti-muscarinics and beta-3 agonists, with no conclusive evidence favoring one OAB medication over another. Common side effects associated with antimuscarinic medications include dry mouth, dry eyes, and constipation. The most common side effect associated with a beta-3 agonist is an increase in blood pressure. Patients should be counseled that a medication trial of 3-4 weeks is required before efficacy is determined.

Finally, women who experience suboptimal efficacy with an OAB medication alone are candidates for percutaneous tibial nerve stimulation (PTNS) with a pelvic floor specialist. PTNS is conducted in the office and patients can continue to use an $\mathrm{OAB}$ medication during their treatment course.

\section{Surgical treatment}

Women with OAB who have failed nonsurgical treatment should be referred to a urologist. Surgical treatments available to address OAB and UUI include bladder Botox ${ }^{\circledR}$ injections and sacral

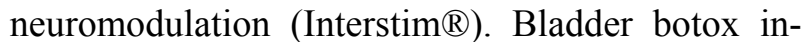
jections can be performed in an office setting, while implantation of the Interstim $\AA$ device requires a minimum of sedation in an operating room setting.

\section{INTERSTITIAL CYSTITIS (IC)/BLADDER HYPERSENSITIVITY}

\section{Pathophysiology}

While the pathophysiology of interstitial cystitis (IC) is not well understood, this diagnosis is often made in patients with chronic bladder pain in the absence of other known etiologies. This disease often coexists with other chronic pain syndromes such as irritable bowel syndrome and fibromyalgia and is thought to be analogous to these chronic pain conditions. However, this terminology is a misnomer as often there is no evidence of inflammation within the bladder, nor is this disease associated with abnormalities within the interstices of the bladder. While little is known about IC and its hypersensitivity symptoms, neurologic upregulation of pain sensation and increased activation of bladder sensory neurons seem to play a significant role in its development [44, 45]. Disruption in the molecular integrity of the glycolsaminoglycan layer of the bladder mucosa which protects the bladder from certain irritants may further exacerbate the condition $[46,47]$.

\section{Clinical presentation}

The chief complaints and presenting symptoms of an IC patient are highly variable and subjective. However, the most consistent feature that patient's present with are increased discomfort with bladder filling and immediate relief with voiding [47, 48]. Other general concerns consistent with IC and bladder hypersensitivity include sensations of pressure, discomfort or spasms of the suprapubic or urethral regions. Other irritative symptoms such as frequency, urgency, and nocturia are also common. Some patients may even be able to identify an inciting event that may trigger or worsen their symptoms such as a UTI, consumption of certain foods, or during the luteal phase of the menstrual cycle [49].

\section{Assessment and diagnosis}

The goal of diagnostic assessment is to exclude other treatable conditions and identify characteristic features of IC. Assessment includes a thorough history taking, physical examination, and urinalysis. History should be focused on voiding symptoms and characteristics of the bladder discomforts. Two standardized questionnaires, namely the IC Symptom and Problem Index and the Genitourinary Pain Index can be used to assess the severity of patient symptoms $[50,51]$. The physical exam should include a pelvic examination and a digital rectal examination to rule out any other underlying disorders. Urinalysis can be used to rule out STI, UTI, or hematuria. Symptoms characterized by bladder discomfort upon bladder filling are a hallmark for IC after all other possible etiologies have been excluded. 


\section{Non-surgical treatment}

Like most conditions, lifestyle modifications and non-surgical treatment options should be pursued first. Behavioral modifications include the application of cold or heat locally over the area of discomfort and avoidance of any food or activities that may exacerbate IC symptoms. For IC and hypersensitive bladder, analgesics such as phenazopyridine can be used as a short-term relief to minimize pain and maximize function during an episodic flare-up. For longer-term medications, amitriptyline is often suggested as the first-line oral medication [52]. Other recommended medications include pentosan polysulfate sodium or antihistamines such as hydroxyzine or cimetidine [53]. If these oral medications do not work, other alternative therapies including bladder hydrodistention, intravesical instillation with dimethyl sulfoxide, intradetrusor injection of botulinum toxin and sacral neuromodulation can be considered. Observational studies assessing the efficacy of these therapeutic options remain scarce and among small sample sizes only [54-57]. Larger, prospective, randomized studies are required to further investigate the durability and safety of these treatments.

\section{Surgical treatment}

After all else fails, there is an option to pursue surgery for the amelioration of bladder discomfort and symptoms secondary to IC or hypersensitivity. Urinary diversion involves diverting urine from the bladder into a continent catheterizable urine pouch or an incontinent urostomy, with the possibility for removal of the bladder at the same time. As such, symptomatic relief can potentially be obtained as bladder filling and distention is no longer possible. These complex reconstructive surgeries can reliably relieve hypersensitivity and irritative symptoms, but pelvic pain may sometimes persist even if a cystectomy is performed $[58,59]$.

\section{DYSFUNCTIONAL VOIDING (DV)}

\section{Pathophysiology}

Dysfunctional voiding (DV) is a disorder caused by dyssynergic striated sphincteric activity at the level of striated urethral sphincter-pelvic floor complex (SUS-PFC). Individuals with this disorder do not have any association with any apparent neurological disease or injury. The DV disorder is considered habitual, as the result of a child learning the wrong habits to contract the
SUS-PFC during voiding as opposed to relaxing it. These habits may form in part due to a response to urgency, pelvic discomfort, or with inappropriate toilet training.

\section{Clinical presentation}

Patients with DV often present with urinary incontinence throughout the day. They may also present with LUTS such as frequency, urgency, nocturia and nocturnal enuresis [60]. Storage symptoms are the most common presenting symptom and may sometimes be the only symptom [61].

\section{Assessment and diagnosis}

The American Urological Association Symptom Score (AUASS) can be used to assess the severity of a patient's DV, with authors deriving a cutoff of 6 for girls and 9 for boys to diagnose DV. Other authors have also created different scoring symptoms, namely the "wetting and functional voiding disorder" scoring system by Akbal et al. and 14-item Likert scale questionnaire by Afshar et al. as aids to diagnose patients with DV $[62,63]$. Besides this, uroflow and urodynamics studies are also essential to diagnose DV. Repeated demonstration of a staccato, interrupted pattern on uroflow is classic for DV as urinary sphincters do not relax entirely during voiding. The definitive test to diagnose DV is visualizing bladder outlet obstruction secondary to dyssynergic external sphincteric activity on urodynamics testing [64].

\section{Non-surgical treatment}

Lifestyle modifications for DV include hypnosis, bladder retraining, and biofeedback to the pelvic floor with conservative urotherapy. All have the primary goal of enabling the patient to relax the bladder outlet during voiding. Anticholinergic medications such as $\alpha$-adrenergic blockers may also serve to relax the bladder neck. In certain situations, some patients may even benefit from sphincteric injection with botulinum toxin [65]. In refractory cases of $\mathrm{DV}$, sacral neuromodulation with the Interstim device or percutaneous tibial nerve stimulation has proved to be a safe, durable and efficacious method in treating DV [66-68].

\section{BLADDER NECK DYSFUNCTION (BND)}

\section{Pathophysiology}

Primary bladder neck dysfunction (BND) refers to a functional impedance of urinary flow at 
the level of the bladder neck. BND, however, develops when the bladder neck hypertrophies, becomes less elastic and increasingly more obstructive, which impedes urine flow. It is hypothesized that there is a neurological component linked to this disorder as studies have shown a relative increase in the density of neuropeptide $\mathrm{Y}$ immunoreactive nerves and exaggeration of the sympathetic nervous system in the bladder neck [69, 70]. Additionally, others have also noted the aberrant orientation of detrusor and bladder neck muscle fibers resulting in the narrowing of the bladder neck [71].

\section{Clinical presentation}

Patients with BND often present with a combination of symptoms, with the most common being hesitancy, pelvic discomfort, frequency, urgency, hesitancy and sense of incomplete emptying or impaired stream. Occasionally, patients may have a history of constipation or previous UTI or encopresis [72].

\section{Assessment and diagnosis}

Urodynamic studies are often required to make the definitive diagnosis of BND. On video urodynamics, patients present with inadequate or delayed bladder neck funneling during voiding, quiet pelvic floor throughout voiding, diminished uroflow despite adequate detrusor contraction and prolonged opening time [73, 74]. Additionally, electromyography (EMG) can be done together with the video urodynamics to show a prolonged pelvic floor EMG lag time ( $>6$ seconds) to reinforce the diagnosis further [75]. If ultrasound studies are obtained, there may be evidence of bladder wall thickening and elevated post-void residual volume. Overall, evidence of diminished urine flow rates in the presence of high voiding detrusor pressures is the hallmarks of obstruction.

\section{Non-surgical treatment}

Biofeedback therapy with pelvic floor manipulations, timed voiding, and anticholinergic medications do not seem to be effective in treating BND as the autonomic nervous system primarily controls the bladder neck. To date, $\alpha$-adrenergic antagonists have remained the first-line medical therapy for BND [76]. Tamsulosin seems to be the most tolerable $\alpha$-blocker with similar efficacy among children.

\section{Surgical treatment}

Patients with delayed treatment for BND may develop worsening detrusor dysfunction such that they become resistant to medical therapies such as $\alpha$-blocker. In such cases, surgical management, such as the transurethral incision of the prostate or bladder neck, may be warranted [77, 78]. Due to the more invasive fashion of these treatment alternatives, there is an increased risk of sexual dysfunction such as retrograde ejaculation.

\section{CONCLUSION}

Voiding dysfunction is a common complaint in both men and women, and although it can be difficult for patients to talk about due to the intimate anatomy and nature of this condition, it nonetheless has major quality of life implications and carries a great cost to society. As the workforce shortage in urology grows, it is vital that other practitioners, namely primary care, step in to provide the proper care to these patients. Accordingly, these clinicians should be able to recognize the varying conditions associated with voiding dysfunction, evaluate and treat these patients with first-line therapies, and be able to identify which patients require a referral to an urologist.

Source of Funding. No funding was provided for the creation of this manuscript.

Acknowledgement. None.

Conflict of Interest. The authors declare that there are not conflicts of interest.

O scădere a forței de muncă a urologilor este prevăzută în Statele Unite în decadele viitoare. In lumina acestor date managementul unor afecțiuni urologice va fi preluat de către medici din alte specialități. Medicii de familie sunt prima linie de intervenție şi cel mai probabil ei vor trata aceste afecțiuni. Una dintre cele mai frecvente afecțiuni urologice este pieredera involuntară de urină. Incidența acesteia creşte odată cu vârsta, considerându-se că mai mult de $50 \%$ dintre pacienții în vârstă suferă de această afecțiune. În ciuda prevalenței înalte şi al impactului negativ asupra calității vieții puțini pacienți doresc să se trateze 
întrucât puțini recunosc simptomele. Scopul acestui review este de a prezenta evaluarea şi abordarea terapeutică a incontinenței urinare la pacienții de gen feminin şi masculin.

Correspondence to: Costas D. Lallas, MD, FACS, 1025 Walnut St, Ste 1100, Philadelphia, PA 19107, Telephone: 215-955-1416

E-mail: Costas.Lallas@jefferson.edu

\section{REFERENCES}

1. NASSAU, D., J. GERBER, AND J. WEISS, The prevalence and treatment of voiding dysfunction in the elderly. 2014, Springer US: Current Geriatrics Reports. p. 33-41.

2. SHAMLIYAN, T.A., et al., Male urinary incontinence: prevalence, risk factors, and preventive interventions. Rev Urol, 2009. 11(3): p. 145-65.

3. WU, J.M., et al., Prevalence and trends of symptomatic pelvic floor disorders in U.S. women. Obstet Gynecol, 2014. 123(1): p. 141-8.

4. HU, T.W., et al., Costs of urinary incontinence and overactive bladder in the United States: a comparative study. Urology, 2004. 63(3): p. 461-5.

5. PRUTHI, R.S., et al., Recent trends in the urology workforce in the United States. Urology, 2013. 82(5): p. 987-93.

6. HAYLEN, B.T., et al., An International Urogynecological Association (IUGA)/International Continence Society (ICS) joint report on the terminology for female pelvic floor dysfunction. Int Urogynecol J, 2010. 21(1): p. 5-26.

7. RADADIA, K.D., et al., Management of postradical prostatectomy urinary incontinence: a review. Urology, 2018. 113: p. 13-19.

8. THÜROFF, J.W., et al., EAU guidelines on urinary incontinence. Eur Urol, 2011. 59(3): p. 387-400.

9. CHUNG, E., D.J. KATZ, AND C. LOVE, Adult male stress and urge urinary incontinence - A review of pathophysiology and treatment strategies for voiding dysfunction in men. Aust Fam Physician, 2017. 46(9): p. 661-666.

10. FLORATOS, D.L., et al., Biofeedback vs verbal feedback as learning tools for pelvic muscle exercises in the early management of urinary incontinence after radical prostatectomy. BJU Int, 2002. 89(7): p. 714-9.

11. TIENFORTI, D., et al., Efficacy of an assisted low-intensity programme of perioperative pelvic floor muscle training in improving the recovery of continence after radical prostatectomy: a randomized controlled trial. BJU Int, 2012. 110(7): p. 1004-10.

12. DEMAAGD, G.A. and T.C. DAVENPORT, Management of urinary incontinence. P T, 2012. 37(6): p. 345-361H.

13. LEE, S.W., et al., Treatment outcomes of transurethral macroplastique injection for postprostatectomy incontinence. Korean J Urol, 2014. 55(3): p. 182-9.

14. CHUNG, E., Contemporary surgical devices for male stress urinary incontinence: a review of technological advances in current continence surgery. Transl Androl Urol, 2017. 6(Suppl 2): p. S112-S121.

15. KIM, S.P., et al., Long-term durability and functional outcomes among patients with artificial urinary sphincters: a 10-year retrospective review from the University of Michigan. J Urol, 2008. 179(5): p. 1912-6.

16. LEPOR, H., Pathophysiology of lower urinary tract symptoms in the aging male population. Rev Urol, 2005. 7 Suppl 7: p. S3-S11.

17. WEI, J.T., E. CALHOUN, and S.J. JACOBSEN, Urologic diseases in America project: benign prostatic hyperplasia. J Urol, 2005. 173(4): p. 1256-61.

18. BLANKSTEIN, U., B. VAN ASSELDONK, and D.S. ELTERMAN, BPH update: medical versus interventional management. Can J Urol, 2016. 23(Suppl 1): p. 10-5.

19. PORST, H., et al., Efficacy and safety of tadalafil once daily in the treatment of men with lower urinary tract symptoms suggestive of benign prostatic hyperplasia: results of an international randomized, double-blind, placebo-controlled trial. Eur Urol, 2011. 60(5): p. 1105-13.

20. SIVARAJAN, G., et al., The role of minimally invasive surgical techniques in the management of large-gland benign prostatic hypertrophy. Rev Urol, 2015. 17(3): p. 140-9.

21. HAYLEN, B.T., et al., An International Urogynecological Association (IUGA)/International Continence Society (ICS) joint report on the terminology for female pelvic floor dysfunction. Neurourol Urodyn, 2010. 29(1): p. 4-20.

22. CHUNG, A., et al., Voiding dysfunction in older men. Curr Opin Urol, 2016. 26(2): p. 177-83.

23. TUBARO, A., Defining overactive bladder: epidemiology and burden of disease. Urology, 2004. 64(6 Suppl 1): p. 2-6.

24. TSE, V., et al., Conjoint Urological Society of Australia and New Zealand (USANZ) and Urogynaecological Society of Australasia (UGSA) Guidelines on the management of adult non-neurogenic overactive bladder. BJU Int, 2016. 117(1): p. 34-47.

25. DMOCHOWSKI, R.R., A. GOMELSKY, Overactive bladder in males. Ther Adv Urol, 2009. 1(4): p. 209-21.

26. BURTON, C., A. SAJJA, P.M. LATTHE, Effectiveness of percutaneous posterior tibial nerve stimulation for overactive bladder: a systematic review and meta-analysis. Neurourol Urodyn, 2012. 31(8): p. 1206-16.

27. OSMAN, N.I., et al., Detrusor underactivity and the underactive bladder: a new clinical entity? A review of current terminology, definitions, epidemiology, aetiology, and diagnosis. Eur Urol, 2014. 65(2): p. 389-98.

28. OSMAN, N.I., F. ESPERTO,C.R. CHAPPLE, Detrusor underactivity and the underactive bladder: a systematic review of preclinical and clinical studies. Eur Urol, 2018. 74(5): p. 633-643.

29. JIANG, Y.H., H.C. KUO, Urothelial barrier deficits, suburothelial inflammation and altered sensory protein expression in detrusor underactivity. J Urol, 2017. 197(1): p. 197-203. 
30. ALDAMANHORI, R., C.R. CHAPPLE, Underactive bladder, detrusor underactivity, definition, symptoms, epidemiology, etiopathogenesis, and risk factors. Curr Opin Urol, 2017. 27(3): p. 293-299.

31. CHAPPLE, C.R., et al., The underactive bladder: a new clinical concept? Eur Urol, 2015. 68(3): p. 351-3.

32. KIM, M., C.W. JEONG, S.J. OH, Effect of preoperative urodynamic detrusor underactivity on transurethral surgery for benign prostatic hyperplasia: a systematic review and meta-analysis. J Urol, 2018. 199(1): p. 237-244.

33. GROSS, C., et al., Sacral neuromodulation for nonobstructive urinary retention: a meta-analysis. Female Pelvic Med Reconstr Surg, 2010. 16(4): p. 249-53.

34. RADEMAKERS, K.L., et al., Prediction of sacral neuromodulation treatment success in men with impaired bladder emptyingtime for a new diagnostic approach. Neurourol Urodyn, 2017. 36(3): p. 808-810.

35. DELANCEY, J.O., Structural support of the urethra as it relates to stress urinary incontinence: the hammock hypothesis. Am J Obstet Gynecol, 1994. 170(6): p. 1713-20; discussion 1720-3.

36. NAKAMURA, R., et al., Outpatient mid-urethral tissue fixation system sling for urodynamic stress urinary incontinence: 3-year surgical and quality of life results. Int Urogynecol J, 2017. 28(11): p. 1733-1738.

37. CAVKAYTAR, S., et al., Effect of home-based Kegel exercises on quality of life in women with stress and mixed urinary incontinence. J Obstet Gynaecol, 2015. 35(4): p. 407-10.

38. BUMP, R.C., et al., Assessment of Kegel pelvic muscle exercise performance after brief verbal instruction. Am J Obstet Gynecol, 1991. 165(2): p. 322-7; discussion 327-9.

39. KIRCHIN, V., et al., Urethral injection therapy for urinary incontinence in women. Cochrane Database Syst Rev, 2017. 7: p. CD003881.

40. FORD, A.A., et al., Mid-urethral sling operations for stress urinary incontinence in women. Cochrane Database Syst Rev, 2017. 7: p. CD006375.

41. STEWART, W.F., et al., Prevalence and burden of overactive bladder in the United States. World J Urol, 2003. 20(6): p. $327-36$.

42. LIU, R.T., et al., Prevalence of overactive bladder and associated risk factors in 1359 patients with type 2 diabetes. Urology, 2011. 78(5): p. 1040-5.

43. DMOCHOWSKI, R.R., et al., Bladder-health diaries: an assessment of 3-day vs 7-day entries. BJU Int, 2005. 96(7): p. $1049-54$.

44. WESSELMANN, U., Interstitial cystitis: a chronic visceral pain syndrome. Urology, 2001. 57(6 Suppl 1): p. 32-9.

45. NAZIF, O., J.M. TEICHMAN, G.F. GEBHART, Neural upregulation in interstitial cystitis. Urology, 2007. 69(4 Suppl): p. $24-33$.

46. GRAHAM, E., T.C. CHAI, Dysfunction of bladder urothelium and bladder urothelial cells in interstitial cystitis. Curr Urol Rep, 2006. 7(6): p. 440-6.

47. HURST, R.E., et al., A deficit of chondroitin sulfate proteoglycans on the bladder uroepithelium in interstitial cystitis. Urology, 1996. 48(5): p. 817-21.

48. TEICHMAN, J.M., C.L. PARSONS, Contemporary clinical presentation of interstitial cystitis. Urology, 2007. 69(4 Suppl): p. 41-7.

49. POWELL-BOONE, T., et al., Menstrual cycle affects bladder pain sensation in subjects with interstitial cystitis. J Urol, 2005. 174(5): p. 1832-6.

50. O'LEARY, M.P., et al., The interstitial cystitis symptom index and problem index. Urology, 1997. 49(5A Suppl): p. 58-63.

51. CLEMENS, J.Q., et al., Validation of a modified National Institute of Health chronic prostatitis symptom index to assess genitourinary pain in both men and women. Urology, 2009. 74(5): p. 983-7, quiz 987.e1-3.

52. FOSTER, H.E., et al., Effect of amitriptyline on symptoms in treatment of naïve patients with interstitial cystitis/painful bladder syndrome. J Urol, 2010. 183(5): p. 1853-8.

53. HANNO, P.M., et al., AUA guideline for the diagnosis and treatment of interstitial cystitis/bladder pain syndrome. J Urol, 2011. 185(6): p. 2162-70.

54. DUNN, M., et al., Interstitial cystitis, treated by prolonged bladder distension. Br J Urol, 1977. 49(7): p. 641-5.

55. YAMADA, T., T. MURAYAMA, M. ANDOH, Adjuvant hydrodistension under epidural anesthesia for interstitial cystitis. Int J Urol, 2003. 10(9): p. 463-8; discussion 469.

56. KUO, H.C., et al., Intravesical botulinum toxin-A injections reduce bladder pain of interstitial cystitis/bladder pain syndrome refractory to conventional treatment - A prospective, multicenter, randomized, double-blind, placebo-controlled clinical trial. Neurourol Urodyn, 2016. 35(5): p. 609-14.

57. PETERS, K.M., K.M. FEBER, R.C. BENNETT, A prospective, single-blind, randomized crossover trial of sacral vs pudendal nerve stimulation for interstitial cystitis. BJU Int, 2007. 100(4): p. 835-9.

58. RÖSSBERGER, J., et al., Long-term results of reconstructive surgery in patients with bladder pain syndrome/interstitial cystitis: subtyping is imperative. Urology, 2007. 70(4): p. 638-42.

59. NORDLING, J., J.G. BLAIVAS, Should urinary diversion for bladder pain syndrome/interstitial cystitis include cystectomy? No. J Urol, 2014. 191(2): p. 293-5.

60. CHASE, J., et al., The management of dysfunctional voiding in children: a report from the Standardisation Committee of the International Children's Continence Society. J Urol, 2010. 183(4): p. 1296-302.

61. KUO, H.C., Videourodynamic characteristics and lower urinary tract symptoms of female bladder outlet obstruction. Urology, 2005. 66(5): p. 1005-9.

62. AKBAL, C., et al., Dysfunctional voiding and incontinence scoring system: quantitative evaluation of incontinence symptoms in pediatric population. J Urol, 2005. 173(3): p. 969-73.

63. AFSHAR, K., et al., Development of a symptom score for dysfunctional elimination syndrome. J Urol, 2009. 182(4 Suppl): p. 1939-43.

64. SINHA, S., Dysfunctional voiding: A review of the terminology, presentation, evaluation and management in children and adults. Indian J Urol, 2011. 27(4): p. 437-47. 
65. KUO, H.C., Recovery of detrusor function after urethral botulinum A toxin injection in patients with idiopathic low detrusor contractility and voiding dysfunction. Urology, 2007. 69(1): p. 57-61; discussion 61-2.

66. BOWER, W.F., C.K. YEUNG, A review of non-invasive electro neuromodulation as an intervention for non-neurogenic bladder dysfunction in children. Neurourol Urodyn, 2004. 23(1): p. 63-7.

67. ROTH, T.J., et al., Sacral neuromodulation for the dysfunctional elimination syndrome: a single center experience with 20 children. J Urol, 2008. 180(1): p. 306-11; discussion 311.

68. CAPITANUCCI, M.L., et al., Long-term efficacy of percutaneous tibial nerve stimulation for different types of lower urinary tract dysfunction in children. J Urol, 2009. 182(4 Suppl): p. 2056-61.

69. NITTI, V.W., Primary bladder neck obstruction in men and women. Rev Urol, 2005. 7 Suppl 8: p. S12-7.

70. AWAD, S.A., et al., Sympathetic activity in the proximal urethra in patients with urinary obstruction. J Urol, 1976. 115(5): p. 545-7.

71. BATES, C.P., E.P. ARNOLD, D.J. GRIFFITHS, The nature of the abnormality in bladder neck obstruction. Br J Urol, 1975. 47(6): p. 651-6.

72. GRAFSTEIN, N.H., A.J. COMBS, K.I. GLASSBERG, Primary bladder neck dysfunction: an overlooked entity in children. Curr Urol Rep, 2005. 6(2): p. 133-9.

73. NITTI, V.W., et al., Lower urinary tract symptoms in young men: videourodynamic findings and correlation with noninvasive measures. J Urol, 2002. 168(1): p. 135-8.

74. NORLEN, L.J., J.G. BLAIVAS, Unsuspected proximal urethral obstruction in young and middle-aged men. J Urol, 1986. 135(5): p. 972-6.

75. COMBS, A.J., et al., Short pelvic floor electromyographic lag time: a novel noninvasive approach to document detrusor overactivity in children with lower urinary tract symptoms. J Urol, 2013. 189(6): p. 2282-6.

76. SMEY, P., L.R. KING, C.F. FIRLIT, Dysfunctional voiding in children secondary to internal sphincter dyssynergia: treatment with phenoxybenzamine. Urol Clin North Am, 1980. 7(2): p. 337-47.

77. KAPLAN, S.A., A.E. TE, B.Z. JACOBS, Urodynamic evidence of vesical neck obstruction in men with misdiagnosed chronic nonbacterial prostatitis and the therapeutic role of endoscopic incision of the bladder neck. J Urol, 1994. 152(6 Pt 1): p. 2063-5.

78. TROCKMAN, B.A., et al., Primary bladder neck obstruction: urodynamic findings and treatment results in 36 men. J Urol, 1996. 156(4): p. 1418-20.

Received $12^{\text {th }}$ February 2019 